\title{
In silico studies of selected xanthophylls as potential candidates against SARS-CoV-2 targeting main protease (Mpro) and papain-like protease (PLpro)
}

${ }^{1}$ Chair and Department of Medical Microbiology

Poznań University of Medical Sciences

Wieniawskiego 3

61-712 Poznań, Poland

${ }^{2}$ Department of Biotechnology

Institute of Natural Fibres and Medicinal Plants - National Research Institute

Wojska Polskiego 71b

60-630 Poznań, Poland

${ }^{3}$ Department of Genetic Engineering and Biotechnology

Faculty of Biological Science and Technology

Jashore University of Science and Technology

Jashore-7408, Bangladesh

${ }^{4}$ Laboratory of Computational Biology

Biological Solution Centre (BioSol Centre)

Dhaka, Bangladesh

*corresponding author: e-mail: tkarpin@ump.edu.pl

Summary

Introduction: The main protease (Mpro) and the papain-like protease (PLpro) are essential for the replication of SARS-CoV-2. Both proteases can be targets for drugs acting against SARS-CoV-2.

Objective: This paper aims to investigate the in silico activity of nine xanthophylls as inhibitors of Mpro and PLpro.

Methods: The structures of Mpro (PDB-ID: 6LU7) and PLpro (PDB-ID: 6W9C) were obtained from RCSB Protein Data Bank and developed with BIOVIA Discovery Studio. Active sites of proteins were performed 
using CASTp. For docking the PyRx was used. Pharmacokinetic parameters of ADMET were evaluated using SwissADME and pkCSM.

Results: $\beta$-cryptoxanthin exhibited the highest binding energy: $-7.4 \mathrm{kcal} / \mathrm{mol}$ in the active site of Mpro. In PLpro active site, the highest binding energy had canthaxanthin of $-9.4 \mathrm{kcal} / \mathrm{mol}$, astaxanthin $-9.3 \mathrm{kcal} / \mathrm{mol}$, flavoxanthin $-9.2 \mathrm{kcal} / \mathrm{mol}$ and violaxanthin $-9.2 \mathrm{kcal} / \mathrm{mol}$. ADMET studies presented lower toxicity of xanthophylls in comparison to ritonavir and ivermectin.

Conclusion: Our findings suggest that xanthophylls can be used as potential inhibitors against SARS-CoV-2 main protease and papain-like protease.

Key words: coronavirus, COVID-19, pandemics, computer-aided drug design, antiviral

Słowa kluczowe: koronawirus, COVID-19, pandemia, projektowanie leków wspomagane komputerowo, działanie przeciwwirusowe

\section{INTRODUCTION}

The SARS-CoV-2 is classified into the Betacoronaviruses genus, in the Riboviria kingdom, Nidovirales order, Coronaviridae family and the Orthocoronavirinae subfamily [1]. SARS-CoV-2 is a large, enveloped virus, which contains positive single-stranded, non-segmented RNA. It has four structural proteins: spike protein $(\mathrm{S})$, nucleocapsid protein $(\mathrm{N})$, membrane glycoprotein (M), and envelope protein (E) [2]. In SARS-CoV-2 are two open reading frames: ORF1a and ORF1ab. ORFs encode polyproteins ppla and pplab, which form the non-structural proteins (NSP 1-16) [3]. NSPs are essential for viral replication. This process is facilitated by main protease (Mpro), also known as 3C-like protease (3CLpro), and the papainlike protease (PLpro). Both proteases can be targets for anti-SARS-CoV-2 drugs [4]. Recent studies show that main protease can be inhibited by ritonavir and papain-like protease by ivermectin $[5,6]$.

The SARS-CoV-2 coronavirus is responsible for recent pandemics. The virus causes a disease known as COVID-19. As of May 5, 2021, there were 153738171 confirmed cases of COVID-19 worldwide, including 3217281 deaths [7]. Vaccinations against SARS-CoV-2 infection were introduced very quickly [8] research on new ones is still being performed. However, there are no treatment guidelines for COVID-19. Various drugs are used with varying degrees of success. So far, remdesivir is the only drug approved by the Food and Drug Administration (FDA) to treat COVID-19 [9].

Xanthophylls are a group of pigments belonging to carotenoids found in plants and algae. The more common ones are fucoxanthin, astaxanthin, violaxanthin, zeaxanthin, and lutein [10]. Xanthophylls have multi-focal activity. Among others, their antibacterial [11], antibiofilm [12], antioxidant [13, 14], anti-inflammatory $[13,15]$ and anticancer $[16]$ activities have been described. The latest publications indicate that xanthophylls may also have a protective effect in the course of COVID-19 [17, 18]. However, their mechanism of action against SARS-CoV-2 is not known.

One of methods of drug discovery is in silico research, namely computer-aided drug design (CADD). CADD is a cost-effective and fast tool, as compared to traditional methods. It allows the prediction of protein structure and function, identification of small molecule (ligand) interactions, active site residues and the study of protein-ligand interactions. Designing and binding ligands to a protein (target) is referred to as docking. Docking identifies specific hit molecules from among multiple ligands $[19,20]$. In silico studies also determine the safety of a potential drug by prediction of the absorption, distribution, metabolism, excretion, and toxicity (ADMET) profiles [21].

This paper aims to investigate the in silico activity of selected xanthophylls as inhibitors of the main protease (Mpro) and the papain-like protease (PLpro) of SARS-CoV-2.

\section{MATERIALS AND METHODS}

\section{Preparation of ligands and receptor}

The 3D SDF structures of nine xanthophylls (astaxanthin, canthaxanthin, $\beta$-cryptoxanthin, flavoxanthin, fucoxanthin, lutein, neoxanthin, violaxanthin, and zeaxanthin) was downloaded from the PubChem database (fig. 1). Ritonavir and ivermectin were used as control compounds. Using the PyRx 0.8 [23] compounds, energy was minimized and files were converted to the PDBQT format for 
<smiles>CC1=C(/C=C/C(C)=C/C=C/C=C/C=C(C)/C=C/C=C(C)/C=C/C=C(C)/C=C/C2=C(C)C(=O)C(O)CC2(C)C)C(C)(C)CC(O)C1=O</smiles>

astaxanthin<smiles>CC1=C(/C=C/C(C)=C/C=C/C(C)=C/C=C/C=C(C)/C=C/C=C(C)/C=C/C2=C(C)CC(O)CC2(C)C)C(C)(C)CCC1</smiles>

$\beta$-cryptoxanthin

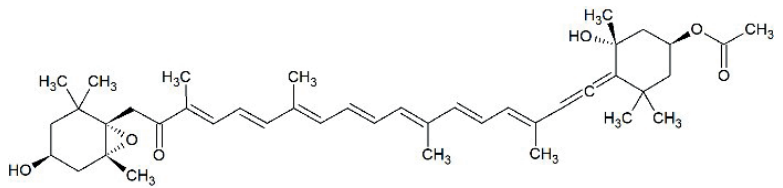

fucoxanthin

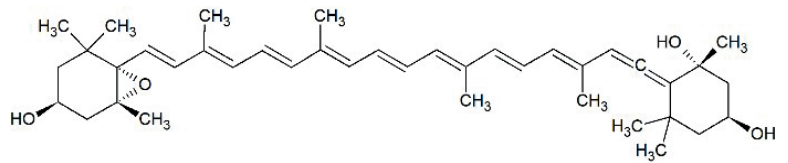

neoxanthin<smiles>CC1=C(/C=C/C=C(C)/C=C/C=C/C(C)=C/C=C/C(C)=C/C=C/C=C(C)/C=C/C2=C(C)CC(O)CC2(C)C)C(C)(C)CC(O)C1</smiles>

zeaxanthin<smiles>CC(C)c1nc(CN(C)C(=O)N[C@H](C(=O)N[C@H](CC[C@H](O)[C@H](Cc2ccccc2)NC(=O)OCc2cncs2)Cc2ccccc2)C(C)C)cs1</smiles>

ritonavir<smiles>CC1=C(/C=C/C(C)=C/C=C/C(C)=C/C=C/C=C(C)/C=C/C=C(C)/C=C/C2=C(C)C(=O)CCC2(C)C)C(C)(C)CCC1=O</smiles>

canthaxanthin<smiles>CC1=C[C@H](O)CC(C)(C)C1/C=C/C(C)=C/C=C/C(C)=C/C=C/C=C(C)/C=C/C=C(C)/C(C)=C\[C@H]1C(C)(C)C[C@@H](O)CC1(C)C</smiles>

flavoxanthin<smiles>CC1=C[C@H](O)CC(C)(C)C1/C=C/C(C)=C/C=C/C(C)=C/C=C/C=C(C)/C=C/C=C(C)/C=C/C1=C(C)CC(O)CC1(C)C</smiles>

lutein

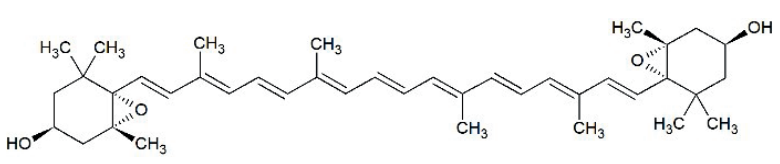

violaxanthin

Figure 1.

Chemical structures of the selected molecules for computational studies

docking. The structures of the SARS-CoV-2 main protease (PDB-ID: 6LU7 at a resolution of $2.16 \AA$ ) and the papain-like protease (PDB-ID: 6W9C at a resolution of $2.70 \AA$ ) were obtained from RCSB Protein Data Bank [24]. The hetero-atoms, water, and ligand groups were removed from the structures using BIOVIA Discovery Studio DS2021 [25].

\section{Docking}

Active sites of proteins were performed using the Computed Atlas of Surface Topography of proteins (CASTp) [26]. The active site of 6LU7 was in chain $\mathrm{A}$ and the active site of $6 \mathrm{~W} 9 \mathrm{C}$ was between $\mathrm{A}, \mathrm{B}$ and C chains. 
For docking, the Autodock Vina tool was used compiled in the PyRx 0.8 [23]. The grid boxes had the following values: for 6LU7 dimensions $\mathrm{x}, \mathrm{y}$, z: $25.7459 \AA, 29.2824 \AA$, $30.5270 \AA$, centre $\mathrm{x}, \mathrm{y}, \mathrm{z}$ : -11.1833 $\AA, 14.7388 \AA, 68.9308 \AA$, and for 6W9C dimensions x, y, z: $86.9085 \AA$ А, $88.8525 \AA$ ̊ $95.9205 \AA$, centre x, y, z: -36.8549 ̊, 11.6758 ̊, 38.9205 ̊.

\section{In silico drug-likeness and ADMET prediction}

Drug-likeness properties were calculated using Lipinski's rule of five [27]. According to this rule, the orally active substance should have no more than one violation of the following criteria:

- no more than $5 \mathrm{H}$ bond donors $(\mathrm{OH}, \mathrm{NH}$, and $\mathrm{SH})$;

- no more than $10 \mathrm{H}$ bond acceptors $(\mathrm{N}, \mathrm{O}$, and $\mathrm{S}$ atoms);

- molecular weight less than $500 \mathrm{Da}$;

- octanol-water partition coefficient (log P) lower than 5.

Pharmacokinetic parameters of absorption, distribution, metabolism, excretion, and toxicity (ADMET) were evaluated using SwissADME [29].

Ethical approval: The conducted research is not related to either human or animal use.

\section{RESULTS AND DISCUSSION}

In silico studies allow for fast prediction of activity and toxicity of natural compounds. SARS-CoV-2 computational analyses are important in searching for ac- tive drugs or designing vaccines [30-34]. The main protease (Mpro) and the papain-like protease (PLpro) can be targets for anti-SARS-CoV-2 drugs. Research in this direction is prevalent and concerns mainly common natural compounds or repurposing of already used drugs [35-38]. Studies presented in this article are first concerning the activity of xanthophylls against SARS-CoV-2.

Results indicate that some xanthophylls exhibited binding energies similar to control drugs. In the case of the main protease, the binding energy of ritonavir was $-7.7 \mathrm{kcal} / \mathrm{mol}$, whereas $\beta$-cryptoxanthin was $-7.4 \mathrm{kcal} / \mathrm{mol}$. In papain-like protease, the binding energy of ivermectin was $-9.5 \mathrm{kcal} / \mathrm{mol}$, whereas for canthaxanthin was $-9.4 \mathrm{kcal} / \mathrm{mol}$, for astaxanthin $-9.3 \mathrm{kcal} / \mathrm{mol}$, and for both flavoxanthin and violaxanthin was $-9.2 \mathrm{kcal} / \mathrm{mol}$ (tab. 1). Amino acid residues involved in interactions between viral proteases and leads with the best binding energies are presented in figures 2-7.

It was found that all the tested xanthophylls violated two rules of Lipinski, namely molecular weight and $\log$ P. This means that all compounds are poorly soluble in water and have low gastrointestinal absorption. Therefore, it would be necessary to create, for example, nanoparticles to increase the availability of xanthophylls. Ritonavir and ivermectin, used as controls, also have two violations of Lipinski's rules (tab. 2).

All the tested xanthophylls do not demonstrate AMES toxicity, hepatotoxicity and skin sensitization. Xanthophylls have oral rat acute and chronic toxicity similar to these of control drugs. What is interesting, ritonavir and ivermectin show hepatotoxicity. It means that xanthophylls are less toxic than these two FDA-accepted drugs (tab. 3).

Table 1.

Free binding energies of the selected xanthophylls and control compounds against SARS-CoV-2

\begin{tabular}{lccc}
\hline \multirow{2}{*}{ Compound } & PubChem ID & Main protease (6LU7) & Papain-like protease (6W9C) \\
\cline { 2 - 4 } & & \multicolumn{2}{c}{ Binding energy [kcal/mol] } \\
\hline Astaxanthin & 5281224 & -6.1 & $\mathbf{- 9 . 3}$ \\
\hline Canthaxanthin & 5281227 & -6.1 & $\mathbf{- 9 . 4}$ \\
\hline$\beta$-Cryptoxanthin & 5281235 & $-\mathbf{7 . 4}$ & -8.8 \\
\hline Flavoxanthin & 5281238 & -6.6 & $\mathbf{- 9 . 2}$ \\
\hline Fucoxanthin & 5281239 & -6.3 & -8.3 \\
\hline Lutein & 5281243 & -6.2 & -9.0 \\
\hline Neoxanthin & 5281247 & -6.9 & -8.8 \\
\hline Violaxanthin & 448438 & -6.5 & $-\mathbf{9 . 2}$ \\
\hline Zeaxanthin & 5280899 & -6.4 & -8.2 \\
\hline Ritonavir & 392622 & -7.7 (control) & -8.7 \\
\hline Ivermectin & 6321424 & -8.1 & $\mathbf{- 9 . 5}$ (control) \\
\hline
\end{tabular}




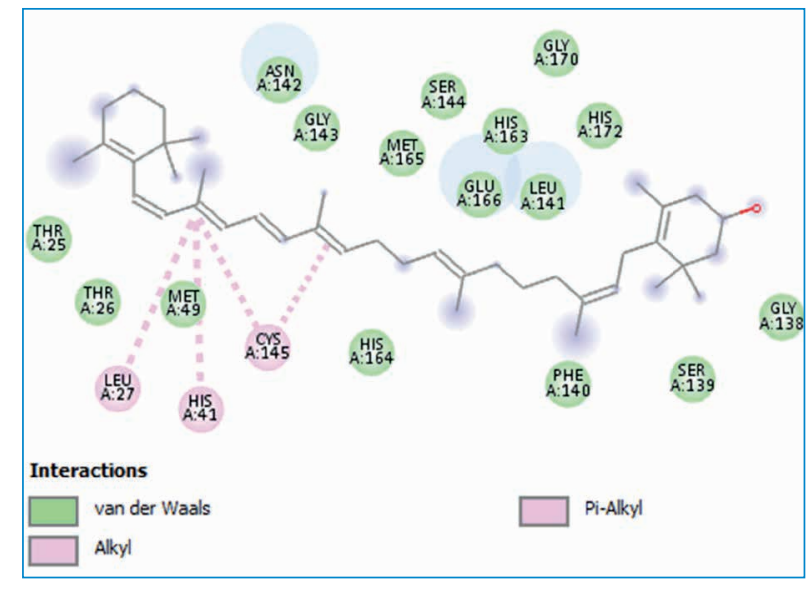

Figure 2.

Interactions of $\beta$-cryptoxanthin docked into the main protease

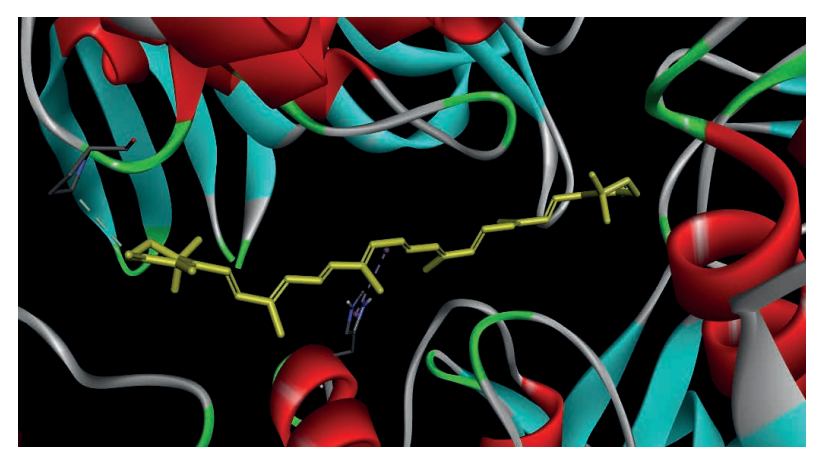

Figure 3.

Canthaxanthin docked into the active site of the papain-like protease

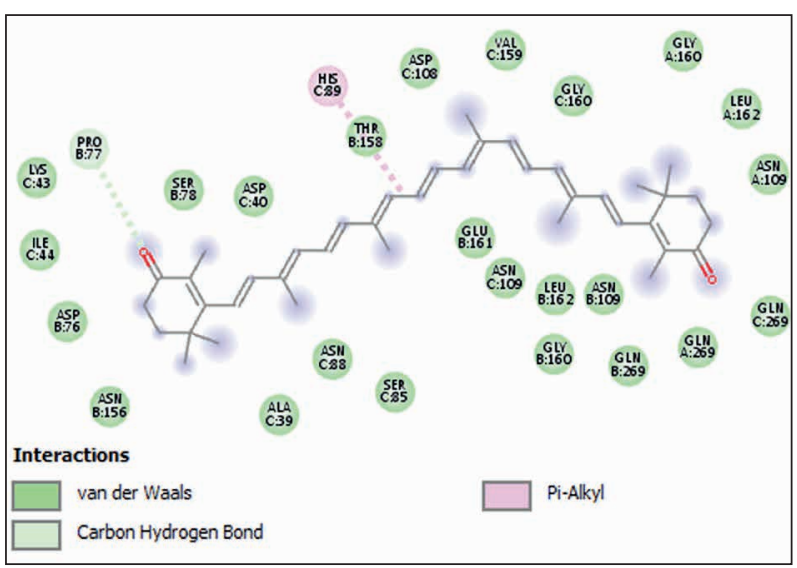

Figure 4.

Interactions of canthaxanthin docked into papain-like protease

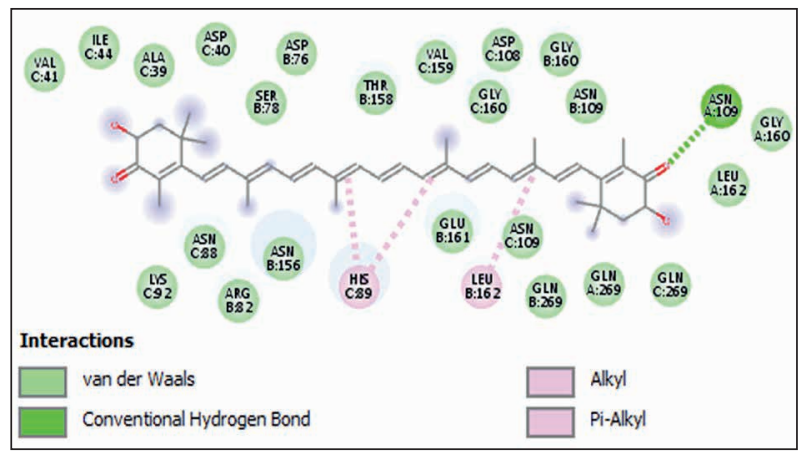

Figure 5.

Interactions of astaxanthin docked into papainlike protease

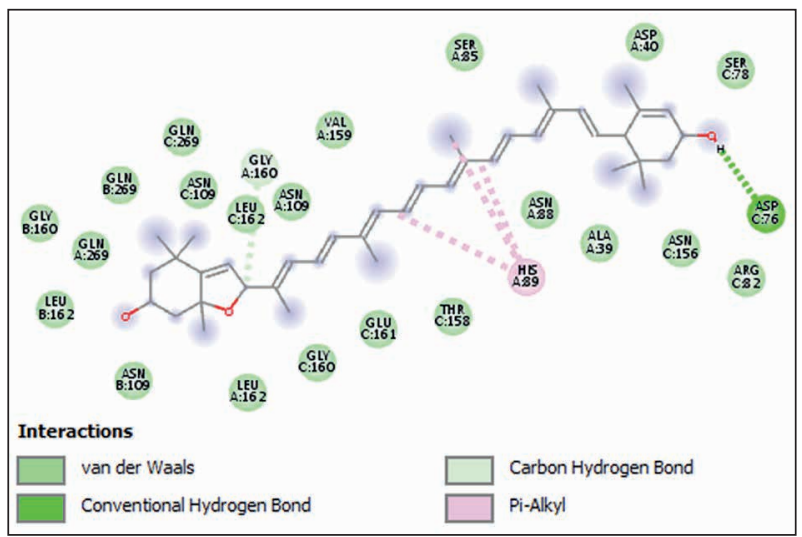

Figure 6.

Interactions of flavoxanthin docked into papainlike protease

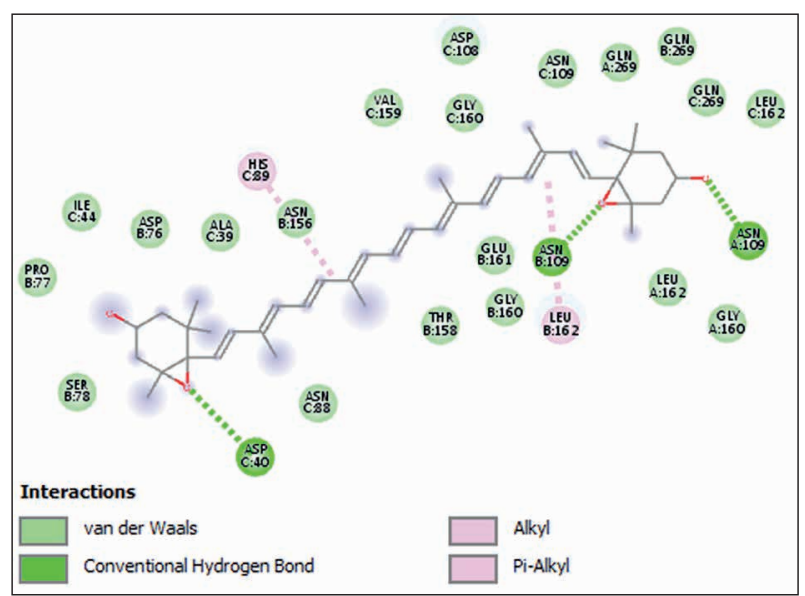

Figure 7.

Interactions of violaxanthin docked into papainlike protease 
Table 2.

Physicochemical properties of the tested xanthophylls

\begin{tabular}{|c|c|c|c|c|}
\hline \multirow[b]{2}{*}{ Compound } & \multicolumn{4}{|c|}{ Lipinski's rule of five } \\
\hline & Molecular weight $(\mathrm{Da})$ & $\begin{array}{c}\text { Partition coefficient } \\
(\log P)\end{array}$ & $\begin{array}{c}\text { Hydrogen bond } \\
\text { donors (HBD) }\end{array}$ & $\begin{array}{l}\text { Hydrogen bond } \\
\text { acceptors (HBA) }\end{array}$ \\
\hline Astaxanthin & 596.84 & 8.24 & 2 & 4 \\
\hline Canthaxanthin & 564.84 & 9.64 & 0 & 2 \\
\hline$\beta$-Cryptoxanthin & 552.87 & 10.20 & 1 & 1 \\
\hline Flavoxanthin & 584.87 & 8.50 & 2 & 3 \\
\hline Fucoxanthin & 658.91 & 7.72 & 2 & 6 \\
\hline Lutein & 568.87 & 9.21 & 2 & 2 \\
\hline Neoxanthin & 600.87 & 7.88 & 3 & 4 \\
\hline Violaxanthin & 600.87 & 8.39 & 2 & 4 \\
\hline Zeaxanthin & 568.87 & 9.31 & 2 & 2 \\
\hline Ritonavir & 720.94 & 5.04 & 4 & 7 \\
\hline Ivermectin & 875.09 & 4.35 & 3 & 14 \\
\hline
\end{tabular}

Table 3.

Predicted toxicity of the tested xanthophylls

\begin{tabular}{|c|c|c|c|c|c|}
\hline Name & AMES toxicity & $\begin{array}{l}\text { Oral rat acute tox. } \\
\qquad \mathrm{LD}_{50}\end{array}$ & $\begin{array}{l}\text { Oral rat chronic } \\
\text { tox. LOAEL }\end{array}$ & Hepatotoxicity & Skin sensitization \\
\hline Astaxanthin & No & 3.515 & 2.173 & No & No \\
\hline Canthaxanthin & No & 2.188 & 2.568 & No & No \\
\hline$\beta$-Cryptoxanthin & No & 2.333 & 0.517 & No & No \\
\hline Flavoxanthin & No & 2.218 & 2.225 & No & No \\
\hline Fucoxanthin & No & 2.428 & 1.146 & No & No \\
\hline Lutein & No & 3.491 & 2.572 & No & No \\
\hline Neoxanthin & No & 2.350 & 2.077 & No & No \\
\hline Violaxanthin & No & 2.132 & 2.054 & No & No \\
\hline Zeaxanthin & No & 3.496 & 2.603 & No & No \\
\hline Ritonavir & no & 2.703 & 2.231 & Yes & No \\
\hline Ivermectin & no & 3.013 & 1.883 & Yes & No \\
\hline
\end{tabular}

\section{CONCLUSIONS}

Some xanthophylls exhibited binding energies similar to drugs used in the treatment of SARSCoV-2 infection. We identified $\beta$-cryptoxanthin as a potent inhibitor of SARS-CoV-2 main protease, and simultaneously canthaxanthin, astaxanthin, flavoxanthin and violaxanthin as inhibitors of papain-like protease. ADMET studies presented that xanthophylls have lower toxicity than ritonavir and ivermectin. Our findings suggest that xanthophylls can be used as potential inhibitors against SARS-CoV-2 main protease and papain-like protease.
Conflict of interest: Authors declare no conflict of interest.

\section{REFERENCES}

1. Zeidler A, Karpinski TM. SARS-CoV, MERS-CoV, SARS-CoV-2 comparison of three emerging coronaviruses. Jundishapur J Microbiol 2020; 13:e103744. doi: https://dx.doi.org/10.5812/jjm.103744

2. Zeidler A, Karpiński TM. What do we know about SARS-CoV-2 virus and COVID-19 disease? J Pre Clin Clin Res 2020; 14:33-38. doi: https://dx.doi. org/10.26444/jpccr/123794. 
3. Finkel Y, Mizrahi O, Nachshon A, WeingartenGabbay S, Morgenstern D, Yahalom-Ronen $\mathrm{Y}$, et al. The coding capacity of SARS-CoV-2. Nature 2021; 589:125-130. doi: https://dx.doi. org/10.1038/s41586-020-2739-1

4. Cherian SS, Agrawal M, Basu A, Abraham P, Gangakhedkar RR, Bhargava B. Perspectives for repurposing drugs for the coronavirus disease 2019. Indian J Med Res 2020; 151:160-171. doi: https://dx.doi.org/10.4103/ijmr.IJMR_585_20

5. Iacob S, Iacob DG. SARS-CoV-2 treatment approaches: numerous options, no certainty for a versatile virus. Front Pharmacol 2020; 11:1224. doi: https://dx.doi.org/10.3389/fphar.2020.01224

6. Mody V, Ho J, Wills S, Mawri A, Lawson L, Ebert MCCJC, et al. Identification of 3-chymotrypsin like protease (3CLPro) inhibitors as potential anti-SARS-CoV-2 agents. Commun Biol 2021; 4:1-10. doi: https://dx.doi.org/10.1038/s42003020-01577-x

7. WHO Coronavirus (COVID-19) Dashboard n.d. https://covid19.who.int (accessed May 5, 2021).

8. Karpiński TM, Ożarowski M, Seremak-Mrozikiewicz A, Wolski H, Włodkowic D. The 2020 race towards SARS-CoV-2 specific vaccines. Theranostics 2021;11:1690-702. https://dx.doi. org/10.7150/thno.53691.

9. Antiviral Therapy. COVID-19 Treatment Guidelines n.d. https://www.covid19treatmentguidelines.nih.gov/antiviral-therapy/ (accessed May 5, 2021).

10. Pereira AG, Otero P, Echave J, Carreira-Casais A, Chamorro F, Collazo N, et al. Xanthophylls from the sea: algae as source of bioactive carotenoids. Mar Drugs 2021; 19:188. doi: https://dx.doi. org/10.3390/md19040188

11. Karpiński TM, Adamczak A. Fucoxanthin - an antibacterial carotenoid. Antioxidants (Basel) 2019; 8:239. doi: https://dx.doi.org/10.3390/antiox 8080239

12. Sampathkumar SJ, Srivastava P, Ramachandran S, Sivashanmugam K, Gothandam KM. Lutein: A potential antibiofilm and antiquorum sensing molecule from green microalga Chlorella pyrenoidosa. Microb Pathog 2019;
135:103658. doi: https://dx.doi.org/10.1016/j. micpath.2019.103658

13. Pap R, Pandur E, Jánosa G, Sipos K, Agócs A, Deli J. Lutein exerts antioxidant and anti-inflammatory effects and influences iron utilization of BV-2 microglia. Antioxidants (Basel) 2021; 10. doi: https://dx.doi.org/10.3390/antiox10030363

14. Uppal S, Dergunov SA, Zhang W, Gentleman S, Redmond TM, Pinkhassik E, et al. Xanthophylls modulate palmitoylation of mammalian $\beta$-carotene oxygenase 2. Antioxidants (Basel) 2021; 10. doi: https://dx.doi.org/10.3390/antiox10030413

15. Oh J, Kim JH, Park JG, Yi Y-S, Park KW, Rho HS, et al. Radical scavenging activity-based and AP-1-targeted anti-inflammatory effects of lutein in macrophage-like and skin keratinocytic cells. Mediators Inflamm 2013; 2013:787042. doi: https://dx.doi.org/10.1155/2013/787042

16. Kim K-N, Heo S-J, Kang S-M, Ahn G, Jeon Y-J. Fucoxanthin induces apoptosis in human leukemia HL-60 cells through a ROS-mediated Bcl-xL pathway. Toxicol In Vitro 2010; 24:1648-1654. doi: https://dx.doi.org/10.1016/j.tiv.2010.05.023

17. Talukdar J, Bhadra B, Dattaroy T, Nagle V, Dasgupta $\mathrm{S}$. Potential of natural astaxanthin in alleviating the risk of cytokine storm in COVID-19. Biomed Pharmacother 2020; 132:110886. doi: https://dx.doi.org/10.1016/j.biopha.2020.110886

18. Tamama K. Potential benefits of dietary seaweeds as protection against COVID-19. Nutr Rev 2020; 2020:nuaa126. doi: https://dx.doi.org/10.1093/ nutrit/nuaa126.

19. Ahammad F, Alam R, Mahmud R, Akhter S, Talukder EK, Tonmoy AM, et al. Pharmacoinformatics and molecular dynamics simulationbased phytochemical screening of neem plant (Azadirachta indica) against human cancer by targeting MCM7 protein. Brief Bioinform 2021:bbab098. doi: https://dx.doi.org/10.1093/ bib/bbab098

20. Ferreira LLG, Andricopulo AD. ADMET modeling approaches in drug discovery. Drug Discov Today 2019; 24:1157-1165. doi: https://dx.doi. org/10.1016/j.drudis.2019.03.015 
21. Agnihotry S, Pathak RK, Srivastav A, Shukla PK, Gautam B. Molecular Docking and structurebased drug design. In: Singh DB. (ed.). Computer-aided drug design. Singapore 2020:115-131. doi: https://dx.doi.org/10.1007/978-981-15-6815-2_6

22. PubChem. PubChem n.d. https://pubchem.ncbi. nlm.nih.gov. Accessed May 5, 2021.

23. Dallakyan S, Olson AJ. Small-molecule library screening by docking with PyRx. Methods Mol Biol 2015; 1263:243-250. doi: https://dx.doi. org/10.1007/978-1-4939-2269-7_19

24. Bank RPD. RCSB PDB: Homepage n.d. https:// www.rcsb.org/. Accessed May 5, 2021.

25. BIOVIA Discovery Studio - BIOVIA - Dassault Systèmes $^{\circledast}$ n.d. https://www.3ds.com/productsservices/biovia/products/molecular-modelingsimulation/biovia-discovery-studio/. Accessed May 5, 2021.

26. Tian W, Chen C, Lei X, Zhao J, Liang J. CASTp 3.0: computed atlas of surface topography of proteins. Nucleic Acids Res 2018; 46:W363-W367. doi: https://dx.doi.org/10.1093/nar/gky473

27. Lipinski CA, Lombardo F, Dominy BW, Feeney PJ. Experimental and computational approaches to estimate solubility and permeability in drug discovery and development settings1PII of original article: S0169-409X(96)00423-1. Adv Drug Del Rev 2001; 46:3-2 doi: 6. https://dx.doi. org/10.1016/S0169-409X(00)00129-0

28. Daina A, Michielin O, Zoete V. SwissADME: a free web tool to evaluate pharmacokinetics, drug-likeness and medicinal chemistry friendliness of small molecules. Sci Rep 2017; 7:42717. doi: https://dx.doi.org/10.1038/srep42717

29. Pires DEV, Blundell TL, Ascher DB. pkCSM: predicting small-molecule pharmacokinetic and toxicity properties using graph-based signatures. J Med Chem 2015; 58:4066-4072. doi: https:// dx.doi.org/10.1021/acs.jmedchem.5b00104

30. Ishack S, Lipner SR. Bioinformatics and immunoinformatics to support COVID-19 vaccine development. J Med Virol 2021;10.1002/jmv.27017. doi: https://dx.doi.org/10.1002/jmv.27017
31. Li X, Yu J, Zhang Z, Ren J, Peluffo AE, Zhang W, et al. Network bioinformatics analysis provides insight into drug repurposing for COVID-19. Med Drug Discov 2021; 10:100090. doi: https:// dx.doi.org/10.1016/j.medidd.2021.100090

32. Amendola G, Ettari R, Previti S, Di Chio C, Messere A, Di Maro S, et al. Lead discovery of SARS-CoV-2 main protease inhibitors through covalent docking-based virtual screening. J Chem Inf Model 2021; 61:2062-2073. doi: https:// dx.doi.org/10.1021/acs.jcim.1c00184

33. Samad A, Ahammad F, Nain Z, Alam R, Imon $\mathrm{RR}$, Hasan $\mathrm{M}$, et al. Designing a multi-epitope vaccine against SARS-CoV-2: an immunoinformatics approach. J Biomol Struct Dyn 2020:10. 1080/07391102.2020.1792347. doi: https://dx.doi. org/10.1080/07391102.2020.1792347

34. Gupta SS, Kumar A, Shankar R, Sharma U. In silico approach for identifying natural lead molecules against SARS-COV-2. J Mol Graph Model 2021; 106:107916. https://dx.doi.org/10.1016/j. jmgm.2021.107916

35. Pekel H, Ilter M, Sensoy O. Inhibition of SARS$\mathrm{CoV}-2$ main protease: a repurposing study that targets the dimer interface of the protein. J Biomol Struct Dyn 2021:1-16. doi: https://dx.doi.org /10.1080/07391102.2021.1910571

36. Wen L, Tang K, Chik KK-H, Chan CC-Y, Tsang JO-L, Liang R, et al. In silico structure-based discovery of a SARS-CoV-2 main protease inhibitor. Int J Biol Sci 2021; 17:1555-1564. doi: https:// dx.doi.org/10.7150/ijbs.59191

37. Ismail MI, Ragab HM, Bekhit AA, Ibrahim TM. Targeting multiple conformations of SARSCoV2 papain-like protease for drug repositioning: An in-silico study. Comput Biol Med 2021; 131:104295. doi: https://dx.doi.org/10.1016/j. compbiomed.2021.104295

38. Jade D, Ayyamperumal S, Tallapaneni V, Joghee Nanjan CM, Barge S, Mohan S, et al. Virtual high throughput screening: Potential inhibitors for SARS-CoV-2 PLPRO and 3CLPRO proteases. Eur J Pharmacol 2021; 901:174082. doi: https:// dx.doi.org/10.1016/j.ejphar.2021.174082 